\title{
Optimum superplasticiser dosage and aggregate proportions for SCC
}

\author{
A. K. H. Kwan and I. Y. T. Ng
}

The University of Hong Kong

An experimental study has been carried out to investigate the effect of superplasticiser dosage on the performance of self-consolidating concrete (SCC). Seven concrete mixes with water/cement (w/c) ratios ranging from 0.35 to 0.45 and fine/total (F/T) aggregate ratios ranging from 0.40 to 0.60 were designed and 42 batches of concrete containing different dosages of superplasticiser were produced. The workability, passing and filling abilities, and segregation stability of the concrete produced were measured using the slump flow, U-box, and sieve segregation tests respectively. For each concrete mix designed, the superplasticiser dosages for maximum slump flow without segregation and maximum filling height were determined. It was found that the maximum performance of the concrete mix and the respective required superplasticiser dosage are dependent on the w/c and F/T aggregate ratios. In general, increasing the F/T aggregate ratio would improve the maximum performance but would also increase the superplasticiser dosage needed. Lastly, the robustness of each concrete mix was evaluated quantitatively as the range of superplasticiser dosage or slump flow satisfying all requirements for SCC. Based on these results, the optimum superplasticiser dosage for maximum robustness of each concrete mix was determined.

\section{Introduction}

Self-consolidating concrete (SCC) is a kind of highperformance concrete having excellent ability to flow under its own weight, pass through narrow gaps between reinforcing bars and obstacles, fill itself into farreaching corners and confined spaces in the mould, and achieve full consolidation without applying compaction. Moreover, it has to have sufficient cohesiveness and stability to avoid segregation after dropping a certain height or flowing a certain distance through narrow gaps along the mould, and sedimentation of coarse aggregate particles after placing at the final position. In other words, SCC must possess, apart from high workability, also high passing ability, filling ability and segregation stability. With these performance attributes, the use of SCC has demonstrated substantial benefits in reducing the number of workers required for concreting, shortening the construction time, improving the productivity and enhancing the quality of the completed concrete structures. Owing to these advantages, SCC

Department of Civil Engineering, The University of Hong Kong, Hong Kong, China

(MACR 80010) Paper received 21 December 2007; last revised 6 July 2008; accepted 16 October 2008 has gained popularity in many places ${ }^{1-4}$ since its successful development.

SCC is not, however, at all easy to produce. It needs to have both high workability and high cohesiveness, which are difficult to achieve simultaneously. In general, any individual measure (e.g. increase of superplasticiser dosage or decrease of fine/total aggregate ratio) that increases the workability would also decrease the cohesiveness. If the cohesiveness is insufficient, the concrete would tend to segregate during and after placing. Furthermore, when passing through closely spaced reinforcing bars and obstacles, the mortar portion would tend to flow ahead of the coarse aggregate, leaving behind the coarse aggregate particles to block the flow of the remaining concrete and thereby reducing the passing and filling abilities of the concrete. On the other hand, because a concrete with higher cohesiveness tends to be more sticky and reluctant to flow, any individual measure (e.g. decrease of superplasticiser dosage or increase of fine/total aggregate ratio) that increases the cohesiveness would also decrease the workability. If the workability is insufficient, the concrete would not be able to flow far during placing and release the entrapped air after placing. It would also have difficulties in passing through narrow gaps and filling itself into far-reaching corners and confined spaces. 
Hence, when designing an SCC, proper balance should be maintained between the workability and cohesiveness that can be achieved at the same time. This is particularly important when determining the superplasticiser (SP) dosage and the fine/total aggregate $(\mathrm{F} / \mathrm{T})$ ratio. As the addition of more SP would increase the workability whereas the addition of excessive SP could decrease the cohesiveness to an unacceptable level, for each concrete mix with given materials and mix proportion, there is an optimum SP dosage for best overall performance in terms of both workability and cohesiveness. The determination of the $\mathrm{F} / \mathrm{T}$ ratio is even more difficult because the $\mathrm{F} / \mathrm{T}$ ratio affects not only the workability and cohesiveness but also the passing and filling abilities. To ensure good passing and filling abilities, the concrete mix should be designed to have a relatively high $\mathrm{F} / \mathrm{T}$ ratio, which increases the cohesiveness, improves the shear deformability by reducing particle interaction (also called interparticle collision) between coarse aggregate particles and decreases the amount of coarse aggregate particles that could be entrapped at narrow gaps. ${ }^{5,6}$ In fact, the F/T ratios adopted for SCC are usually higher than the common values of 0.35 to 0.45 for conventional concrete. ${ }^{7}$ In this regard, Okamura and Ouchi ${ }^{6}$ suggested that the coarse aggregate content should not be larger than $50 \%$ of the total aggregate content. Likewise, $\mathrm{Ng}$ et $a l .{ }^{8}$ recommended that the coarse aggregate content should not be larger than the fine aggregate content (in other words, the $\mathrm{F} / \mathrm{T}$ ratio should be at least $0 \cdot 5)$ whereas the $20 \mathrm{~mm}$ aggregate content should not be larger than the $10 \mathrm{~mm}$ aggregate content.

Another major difficulty in the design and production of SCC is that the performance of the SCC is often very sensitive to small variations in the quantity and/or quality of the ingredients, especially the water content, the SP dosage and compatibility, and the aggregate grading, shape and moisture content. To ease the pressure on production control and reduce the possibility of having problems on the job site, the SCC should be designed to be tolerant to daily fluctuations of the ingredients or, in other words, to have adequate robustness. ${ }^{9}$ To be more specific, the robustness of an SCC is the tolerance of the SCC to expected variations in the ingredients while maintaining the required performance standard. Nkinamubanzi and Aïtcin ${ }^{10}$ have found that the chemical compatibility of the SP used is critical to the robustness of a concrete mix. Nunes et al. ${ }^{11}$ proposed to assess the robustness of an SCC in terms of the frequency of satisfying the acceptance criteria despite daily fluctuations of the ingredients. They found that the mix parameter having the greatest effect on the performance of an SCC is the water-topowder ratio and that the effect of one mix parameter is dependent on the other mix parameters.

During recent trial mixing to optimise the mix design of SCC, the current authors noticed that apart from the water content, the SP dosage also has great effect on the performance of SCC. Quite often, the addition of more SP to increase the workability would gradually decrease the cohesiveness and, at a certain stage, the passing/filling abilities and segregation stability of the concrete mix could drop drastically. Hence, there is a limited acceptable range of SP dosage within which the concrete would perform satisfactorily. Moreover, the $\mathrm{F} / \mathrm{T}$ ratio has great effect on such acceptable range of SP dosage, which, in a way, may be taken as a measure of robustness. In order to study the effect of SP dosage on the performance of $\mathrm{SCC}$ and the effect of $\mathrm{F} / \mathrm{T}$ ratio on the robustness of SCC, a comprehensive experimental programme has been launched. In the experimental programme, a total of 42 batches of concrete with water/cement $(\mathrm{w} / \mathrm{c})$ ratios ranging from 0.35 to 0.45 , $\mathrm{F} / \mathrm{T}$ ratios ranging from 0.40 to 0.60 and SP dosages ranging from 0.6 to $2 \cdot 4 \%$ by weight of the cement content have been produced for performance evaluation, as reported herein.

\section{Experimental details}

\section{Materials}

An ordinary Portland cement of strength class $52 \cdot 5 \mathrm{~N}$ complying with BS 12: $1996^{12}$ was used as the only cementitious material. Its relative density, fineness and 28-day mortar cube strength (tested as per BS EN 196: Part 1: 2005) $)^{13}$ were $3 \cdot 10,336 \mathrm{~m}^{2} / \mathrm{kg}$ and $64 \cdot 4 \mathrm{MPa}$ respectively. Crushed granite rocks were used for both the fine and coarse aggregates. The fine aggregate had nominal maximum size of $5 \mathrm{~mm}$, relative density of $2 \cdot 62$, fineness modulus of 3.26 and water absorption of $1 \cdot 5 \%$, while the coarse aggregate had nominal maximum size of $20 \mathrm{~mm}$, relative density of 2.59 , fineness modulus of 6.46 and water absorption of $0.8 \%$. Figure 1 depicts the grading curves of the fine and coarse aggregates, which fall within the permissible limits stipulated in BS 882: 1992. ${ }^{14}$ The superplasticiser added was a polycarboxylate-based superplasticiser complying with BS 5075: Part 3: $1985 .{ }^{15}$ It was a

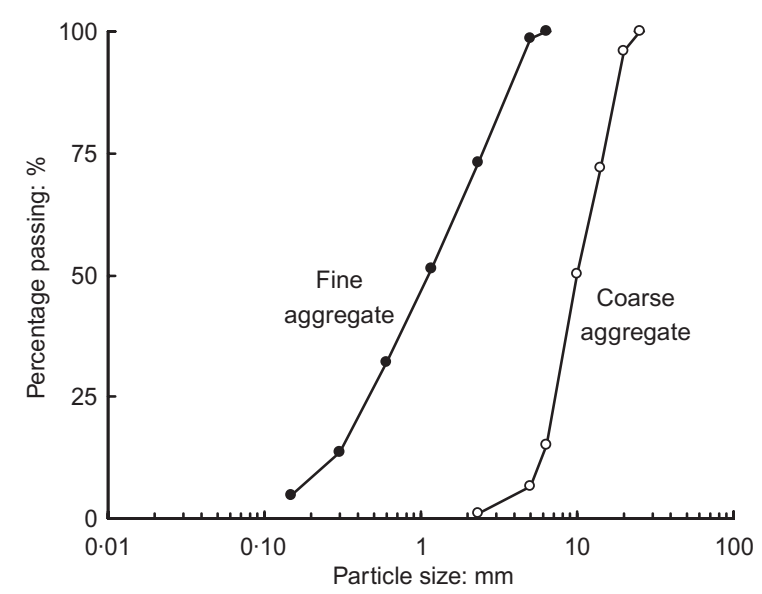

Figure 1. Grading curves of the fine and coarse aggregates

Magazine of Concrete Research, 2009, 61, No. 4 
milky white solution with relative density of 1.05 and solid content of $20 \%$. Its molecules have a comb-like structure consisting of a backbone chain and a number of graft chains. The functional group of the backbone chain produces negative charges to disperse the cement grains (this is called electrostatic repulsion) while the graft chains wrap the cement grains to maintain separation and avoid flocculation of the cement grains (this is called steric hindrance). Table 1 summarises the properties of the materials used.

\section{Mix proportions}

Seven concrete mixes were designed. They are numbered $A$ to $G$. The mixes $A$ and $B$ have a w/c ratio of $0 \cdot 35$, mixes $C, D$ and $E$ have a $\mathrm{w} / \mathrm{c}$ ratio of $0 \cdot 40$, and mixes $F$ and $G$ have a $w / c$ ratio of 0.45 . These $w / c$ ratios should have covered the usual range for production of normal- and high-strength concrete. Apart from the $\mathrm{w} / \mathrm{c}$ ratio, the $\mathrm{F} / \mathrm{T}$ ratio was also varied to investigate their combined effects. Among the two mixes with $\mathrm{w} / \mathrm{c}=0.35, \mathrm{~A}$ and $\mathrm{B}$ have $\mathrm{F} / \mathrm{T}$ ratios of 0.50 and 0.60 respectively. Among the three mixes with $\mathrm{w} / \mathrm{c}=0 \cdot 40$, $\mathrm{C}, \mathrm{D}$ and $\mathrm{E}$ have $\mathrm{F} / \mathrm{T}$ ratios of $0.40,0.50$ and 0.60 respectively. Among the two mixes with $\mathrm{w} / \mathrm{c}=0.45, \mathrm{~F}$ and $\mathrm{G}$ have $\mathrm{F} / \mathrm{T}$ ratios of 0.50 and 0.60 , respectively. In all the concrete mixes, the paste volume was set at $35 \%$ to strike a balance between workability of fresh concrete and dimensional stability of hardened concrete. ${ }^{16}$ The mix parameters and mix proportions of the concrete mixes are summarised in Tables 2 and 3 respectively. For each concrete mix, several batches of concrete having different dosages of SP were produced.

Table 1. Properties of materials

\begin{tabular}{l|l|c}
\hline Material & Property & Measured value \\
\hline Cement & Relative density & $3 \cdot 10$ \\
& Fineness & $336 \mathrm{~m}^{2} / \mathrm{kg}$ \\
Fine aggregate & 28-day mortar cube strength & $64 \cdot 4 \mathrm{MPa}$ \\
& Relative density & $2 \cdot 62$ \\
& Fineness modulus & $3 \cdot 26$ \\
Coarse aggregate & Water absorption & $1 \cdot 5 \%$ \\
& Relative density & $2 \cdot 59$ \\
& Fineness modulus & $6 \cdot 46$ \\
Superplasticiser & Water absorption & $0 \cdot 8 \%$ \\
& Relative density & $1 \cdot 05$ \\
& Solid content & $20 \%$ \\
\hline
\end{tabular}

Each batch of concrete so produced is assigned an identification code $X-Y$, in which $X$ is the concrete mix number and $Y$ is the SP dosage expressed in terms of percentage by weight of the cement content.

\section{Mixing, testing and casting}

An electronic balance was used to weigh the materials and a pan mixer was employed to produce each batch of concrete. During production, the aggregate and cement were first added into the mixer. Then, water was added and mixed with the aggregate and cement for $2 \mathrm{~min}$. After this preliminary mixing, the mixture was left undisturbed for $1 \mathrm{~min}$ to allow water absorption of the aggregate particles. Superplasticiser was then added to the mixture and the mixing resumed and continued for a further $2 \mathrm{~min}$. At the same dosage, such delayed addition of superplasticiser has been proven to yield higher fluidity as compared to simultaneous addition of superplasticiser. ${ }^{17}$

Immediately after completion of the mixing process, concrete samples were taken from the mixer for slump flow test, U-box test and sieve segregation test, which were performed concurrently to avoid workability loss with time. After having carried out these tests, the remaining concrete in the mixer was remixed for $30 \mathrm{~s}$ and then taken out of the mixer for casting three $150 \mathrm{~mm}$ cubes. No tamping or vibration was applied during casting of the cubes; the concrete placed into the moulds was just left to consolidate by itself under its own weight. The top surface of each concrete cube was gently trowelled and then covered with a plastic

Table 2. Mix parameters of concrete mixes

\begin{tabular}{l|c|c|c}
\hline Mix No. & w/c ratio & F/T ratio & $\begin{array}{c}\text { Range of } \\
\text { SP dosage: \% }\end{array}$ \\
\hline A & $0 \cdot 35$ & $0 \cdot 50$ & $0 \cdot 8-1 \cdot 6$ \\
B & $0 \cdot 35$ & $0 \cdot 60$ & $1 \cdot 2-2 \cdot 4$ \\
C & $0 \cdot 40$ & $0 \cdot 40$ & $0 \cdot 7-1 \cdot 2$ \\
D & $0 \cdot 40$ & $0 \cdot 50$ & $0 \cdot 9-1 \cdot 5$ \\
E & $0 \cdot 40$ & $0 \cdot 60$ & $0 \cdot 8-1 \cdot 8$ \\
F & $0 \cdot 45$ & $0 \cdot 50$ & $0 \cdot 6-1 \cdot 1$ \\
G & $0 \cdot 45$ & $0 \cdot 60$ & $0 \cdot 9-1 \cdot 3$ \\
\hline
\end{tabular}

Notes:

(a) The superplasticiser dosage was measured in terms of liquid weight as a percentage by weight of the cement content.

(b) In all concrete mixes, the paste volume was set at $35 \%$.

Table 3. Mix proportions of concrete mixes

\begin{tabular}{l|c|c|c|c|c}
\hline Mix No. & Water: $\mathrm{kg} / \mathrm{m}^{3}$ & Cement: $\mathrm{kg} / \mathrm{m}^{3}$ & Fine aggregate: $\mathrm{kg} / \mathrm{m}^{3}$ & Coarse aggregate: $\mathrm{kg} / \mathrm{m}^{3}$ & Range of SP content: $\mathrm{kg} / \mathrm{m}^{3}$ \\
\hline A & 182 & 520 & 859 & 853 & $4 \cdot 2-8 \cdot 3$ \\
B & 182 & 520 & 1032 & 683 & $6 \cdot 2-12 \cdot 5$ \\
C & 194 & 484 & 887 & 1023 & $3 \cdot 4-5 \cdot 8$ \\
D & 194 & 484 & 1032 & 853 & $4 \cdot 4-7 \cdot 3$ \\
E & 194 & 484 & 859 & 683 & $3 \cdot 9-8 \cdot 7$ \\
F & 204 & 453 & 1032 & 853 & $2 \cdot 7-5 \cdot 0$ \\
G & 204 & 453 & & 683 & $4 \cdot 1-5 \cdot 9$ \\
\hline
\end{tabular}


sheet. After casting, all the cubes were cured in the laboratory with temperature controlled at $24 \pm 2^{\circ} \mathrm{C}$ to allow setting and hardening. At $24 \mathrm{~h}$ after casting, the cubes were demoulded and put into a lime-saturated water curing tank controlled at a temperature of $27 \pm 2{ }^{\circ} \mathrm{C}$ until the age of 28 days for cube compression test.

\section{Slump flow test}

The slump flow test for SCC was very similar to the slump test for conventional concrete stipulated in BS 1881: Part 102: $1983 .{ }^{18}$ In fact, the same apparatus was employed. As for the slump test, the slump flow test was performed on a flat, smooth and level steel plate large enough to contain the concrete patty formed during the test. To measure the slump and slump flow of the concrete, the concrete was first filled into the slump cone, trowelled flat at the top surface and then allowed to deform and flow by lifting the slump cone steadily. Unlike the slump test, no tamping was applied when filling the concrete into the slump cone. After lifting the slump cone, the slump was measured as the drop in height of the concrete and the slump flow was measured as the average diameter of the concrete patty in two perpendicular directions. The slump is a measure of deformability whereas the slump flow is a measure of flowability.

\section{U-box test}

A specially designed U-box, comprising a storing compartment, a filling compartment and an opening between the two compartments, was employed for the U-box test. There are two slightly different versions of U-box in common use: one with a round bottom and the other with a flat bottom. ${ }^{19}$ The U-box employed in this study was the same as that used by $\mathrm{Ng}$ et al., ${ }^{8}$ which is of flat bottom design and has three $12 \mathrm{~mm}$ diameter plain round bars at the opening between the two compartments serving as an obstacle to test the passing ability of the concrete. At the onset of the Ubox test, the sliding gate at the opening was closed and the concrete sample was placed gently into the storing compartment. When the storing compartment was full, the top surface of the concrete was trowelled flat and the sliding gate was opened to allow the concrete to flow under its own weight through the obstacle into the filling compartment. After the flow had ceased, the height of the concrete in the filling compartment was measured and recorded as the filling height of the concrete. This filling height is an integrated measure of the passing and filling abilities of the concrete. The Japan Society of Civil Engineers (JSCE) Guidelines for Concrete $^{20}$ stipulates that the filling height of SCC should be at least $300 \mathrm{~mm}$.

\section{Sieve segregation test}

A $5 \mathrm{~mm}$ perforated steel plate sieve was employed for the sieve segregation test. Several slightly different test procedures have been developed. ${ }^{9,21,22}$ The test procedure adopted in this study was the same as that used by $\mathrm{Ng}$ et al., ${ }^{8}$ which followed the recommendation of the European Guidelines for SCC. ${ }^{9}$ It started with the placing of a 10 litre concrete sample gently into a $300 \mathrm{~mm}$ diameter plastic container. The container was then covered by a lid, put at a level position and left undisturbed to allow sedimentation and bleeding to take place. After $15 \mathrm{~min}$ of waiting, the upper 2 litres of the concrete sample, including any bleeding water, was poured gently onto the sieve at a height of $500 \mathrm{~mm}$. The materials dripping through the sieve (the laitance or paste incapable of adhering to the coarse aggregate particles retained by the sieve) were collected by a base receiver placed underneath the sieve. After $2 \mathrm{~min}$ of waiting, which was deemed sufficient for the dripping to finish, the sieve was removed without agitation. The weight of the materials collected by the base receiver was then measured and the segregation index of the concrete determined as the ratio of the weight of materials in the base receiver to the weight of concrete poured onto the sieve. This segregation index is an integrated measure of the sedimentation of the coarse aggregate particles and the segregation of the concrete. As both sedimentation and segregation are consequences of the concrete having insufficient cohesiveness, the segregation index may also be taken as a measure of the degree of insufficient cohesiveness. According to the European Guidelines for SCC, ${ }^{9}$ the segregation index of SCC should not be higher than $20 \%$.

\section{Experimental results}

The experimental results of the 42 batches of concrete mixes produced are summarised in Tables 4, 5 and 6 for mixes $\mathrm{A}$ and $\mathrm{B}$ with $\mathrm{w} / \mathrm{c}=0 \cdot 35$, mixes $\mathrm{C}, \mathrm{D}$ and $\mathrm{E}$ with $\mathrm{w} / \mathrm{c}=0.40$, and mixes $\mathrm{F}$ and $\mathrm{G}$ with $\mathrm{w} / \mathrm{c}=0 \cdot 45$, respectively. Detailed data analysis of these results is presented in the following subsections.

\section{Effect of superplasticiser on workability}

The effect of superplasticiser on the workability of the seven concrete mixes is depicted in Figure 2 by plotting the slump flow against the SP dosage. For clearer illustration, the curves are grouped into three separated graphs according to the $\mathrm{w} / \mathrm{c}$ ratio of the concrete mix. On the whole, the slump flow increased with the SP dosage at a gradually decreasing rate until the slump flow increased only marginally when the SP dosage was further increased. However, at a given SP dosage, the slump flow was dependent on the w/c ratio and the $\mathrm{F} / \mathrm{T}$ ratio. At a fixed $\mathrm{w} / \mathrm{c}$ ratio, the slump flow at any given SP dosage was lower at a higher $\mathrm{F} / \mathrm{T}$ ratio, or, in other words, the SP dosage required to achieve any required slump flow was higher at a higher $\mathrm{F} / \mathrm{T}$ ratio. This was because a higher $\mathrm{F} / \mathrm{T}$ ratio would in- 
Table 4. Experimental results of mixes $A$ and $B$ with $w / c=0 \cdot 35$

\begin{tabular}{|c|c|c|c|c|c|}
\hline Batch code & Slump: mm & Slump flow: $\mathrm{mm}$ & Filling height: $\mathrm{mm}$ & Segregation index: \% & 28-day cube strength: $\mathrm{MPa}$ \\
\hline A- 0.8 & 89 & 217 & 0 & $0 \cdot 0$ & $73 \cdot 0$ \\
\hline A- $1 \cdot 0$ & 232 & 469 & 225 & $0 \cdot 3$ & $75 \cdot 2$ \\
\hline A- $1 \cdot 2$ & 248 & 623 & 205 & $9 \cdot 3$ & $78 \cdot 2$ \\
\hline A- $1 \cdot 4$ & 261 & 685 & 275 & $11 \cdot 3$ & $82 \cdot 8$ \\
\hline A-1.6 & 270 & 790 & 95 & $27 \cdot 1$ & $86 \cdot 0$ \\
\hline B-1.2 & 211 & 388 & 273 & $0 \cdot 0$ & $69 \cdot 7$ \\
\hline B-1.4 & 257 & 577 & 323 & $1 \cdot 0$ & $78 \cdot 3$ \\
\hline B-1.6 & 266 & 652 & 334 & $2 \cdot 4$ & $80 \cdot 7$ \\
\hline B- $1 \cdot 8$ & 270 & 765 & 338 & $9 \cdot 5$ & $85 \cdot 9$ \\
\hline B-2.0 & 270 & 792 & 338 & $9 \cdot 5$ & $85 \cdot 9$ \\
\hline B-2.2 & 271 & 825 & 337 & $15 \cdot 1$ & $83 \cdot 1$ \\
\hline B-2.4 & 268 & 835 & 336 & $22 \cdot 1$ & 83.7 \\
\hline
\end{tabular}

Table 5. Experimental results of mixes $C, D$ and $E$ with $w / c=0 \cdot 40$

\begin{tabular}{|c|c|c|c|c|c|}
\hline Batch code & Slump: mm & Slump flow: $\mathrm{mm}$ & Filling height: $\mathrm{mm}$ & Segregation index: \% & 28-day cube strength: $\mathrm{MPa}$ \\
\hline$C-0 \cdot 7$ & 240 & 574 & 174 & 0.5 & $64 \cdot 7$ \\
\hline $\mathrm{C}-0.8$ & 256 & 585 & 141 & $5 \cdot 3$ & $65 \cdot 5$ \\
\hline $\mathrm{C}-0 \cdot 9$ & 250 & 629 & 162 & $7 \cdot 8$ & $67 \cdot 5$ \\
\hline $\mathrm{C}-1 \cdot 0$ & 254 & 635 & 170 & $11 \cdot 3$ & $65 \cdot 1$ \\
\hline $\mathrm{C}-1 \cdot 1$ & 250 & 695 & 185 & $15 \cdot 5$ & $70 \cdot 9$ \\
\hline $\mathrm{C}-1 \cdot 2$ & 249 & 741 & 91 & $37 \cdot 1$ & $72 \cdot 0$ \\
\hline D-0.9 & 213 & 416 & 134 & $0 \cdot 0$ & $60 \cdot 5$ \\
\hline D-1.0 & 248 & 553 & 218 & $0 \cdot 8$ & $66 \cdot 0$ \\
\hline $\mathrm{D}-1 \cdot 1$ & 254 & 605 & 246 & $4 \cdot 3$ & $66 \cdot 2$ \\
\hline $\mathrm{D}-1 \cdot 2$ & 255 & 648 & 248 & $5 \cdot 2$ & $66 \cdot 0$ \\
\hline $\mathrm{D}-1 \cdot 3$ & 264 & 702 & 226 & $9 \cdot 8$ & $68 \cdot 6$ \\
\hline D-1·4 & 258 & 715 & 188 & $17 \cdot 4$ & $68 \cdot 8$ \\
\hline D- $1 \cdot 5$ & 258 & 748 & 183 & $25 \cdot 2$ & $70 \cdot 4$ \\
\hline $\mathrm{E}-0 \cdot 8$ & 77 & 234 & 0 & $0 \cdot 0$ & $55 \cdot 8$ \\
\hline E-1.0 & 240 & 498 & 318 & $1 \cdot 6$ & $57 \cdot 3$ \\
\hline E-1.2 & 255 & 538 & 329 & $2 \cdot 5$ & $64 \cdot 9$ \\
\hline E-1.4 & 263 & 662 & 334 & $6 \cdot 8$ & $68 \cdot 2$ \\
\hline E-1.6 & 264 & 753 & 336 & $19 \cdot 0$ & $72 \cdot 3$ \\
\hline E-1.8 & 255 & 810 & 335 & $38 \cdot 8$ & $71 \cdot 4$ \\
\hline
\end{tabular}

Table 6. Experimental results of mixes $F$ and $G$ with $w / c=0.45$

\begin{tabular}{|c|c|c|c|c|c|}
\hline Batch code & Slump: mm & Slump flow: $\mathrm{mm}$ & Filling height: $\mathrm{mm}$ & Segregation index: \% & 28-day cube strength: $\mathrm{MPa}$ \\
\hline $\mathrm{F}-0 \cdot 6$ & 225 & 393 & 200 & $1 \cdot 2$ & $55 \cdot 2$ \\
\hline $\mathrm{F}-0 \cdot 7$ & 232 & 498 & 163 & $2 \cdot 5$ & $56 \cdot 3$ \\
\hline $\mathrm{F}-0 \cdot 8$ & 255 & 588 & 243 & $6 \cdot 4$ & 58.9 \\
\hline $\mathrm{F}-0 \cdot 9$ & 255 & 618 & 247 & $8 \cdot 0$ & $59 \cdot 9$ \\
\hline $\mathrm{F}-1 \cdot 0$ & 256 & 709 & 185 & $15 \cdot 2$ & $64 \cdot 7$ \\
\hline $\mathrm{F}-1 \cdot 1$ & 260 & 736 & 208 & $36 \cdot 5$ & $65 \cdot 1$ \\
\hline G-0.9 & 230 & 434 & 274 & $0 \cdot 1$ & 54.9 \\
\hline $\mathrm{G}-1 \cdot 0$ & 252 & 527 & 310 & $1 \cdot 7$ & $56 \cdot 3$ \\
\hline $\mathrm{G}-1 \cdot 1$ & 255 & 588 & 324 & $4 \cdot 8$ & $60 \cdot 1$ \\
\hline $\mathrm{G}-1 \cdot 2$ & 266 & 692 & 336 & $12 \cdot 9$ & $62 \cdot 0$ \\
\hline $\mathrm{G}-1 \cdot 3$ & 270 & 735 & 306 & $29 \cdot 8$ & $64 \cdot 4$ \\
\hline
\end{tabular}

crease the total surface area of particles to be adsorbed with superplasticiser for particle dispersion, thereby leading to a higher superplasticiser demand. On the other hand, at a fixed $\mathrm{F} / \mathrm{T}$ ratio, the slump flow at any given SP dosage was lower at a lower w/c ratio, or, in other words, the SP dosage required to achieve any required slump flow was higher at a lower w/c ratio. This was because a lower w/c ratio would decrease the 

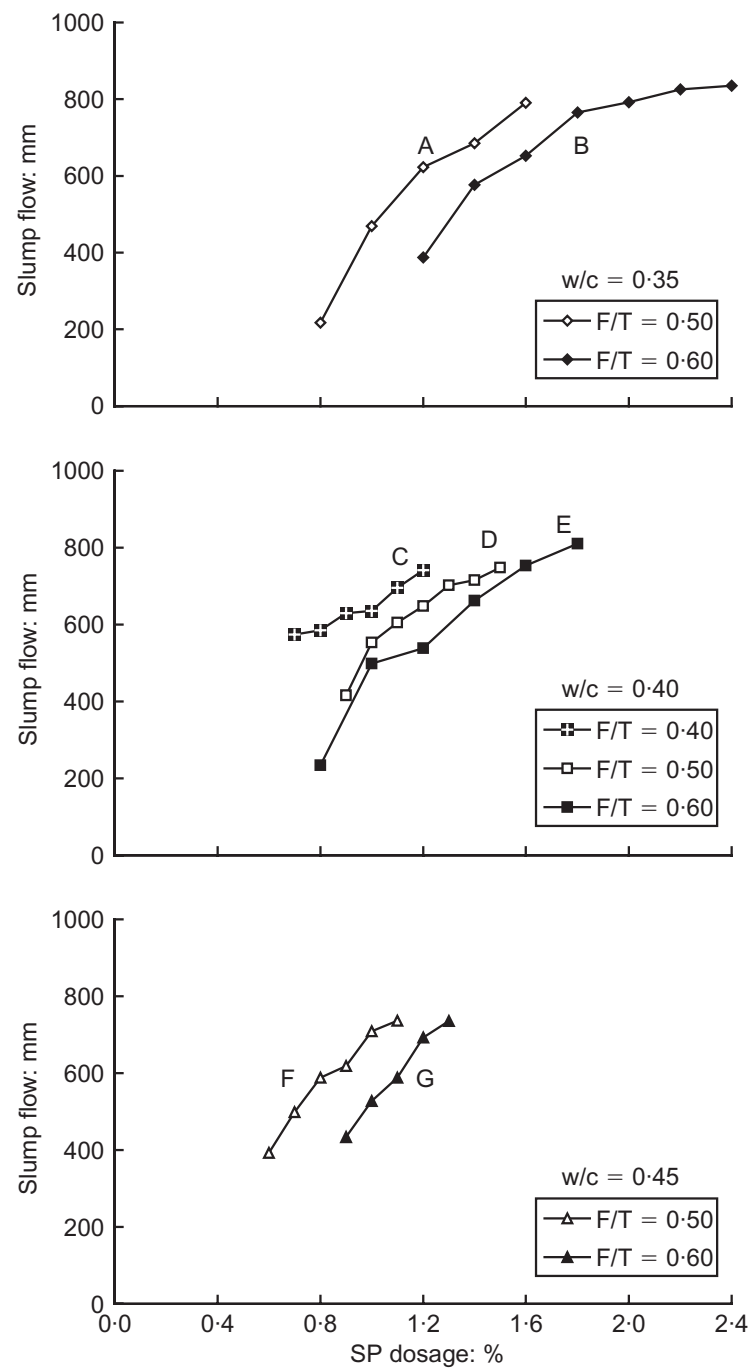

Figure 2. Slump flow plotted against SP dosage

thickness of the water films coating the particles and increase the particle interaction and internal friction between the particles, thereby leading to a higher superplasticiser demand.

\section{Effect of superplasticiser on passing/filling abilities}

The effect of superplasticiser on the passing and filling abilities of the seven concrete mixes is depicted in Figure 3 by plotting the filling height against the SP dosage. As before, the curves are grouped into three separate graphs according to the $\mathrm{w} / \mathrm{c}$ ratio of the concrete mix. In general, the filling height increased with the SP dosage and then after reaching a certain maximum value decreased drastically when the SP dosage was only slightly further increased. As a result, for each concrete mix, there was a certain optimum SP dosage at which the filling height reached a maximum value. The maximum filling height was dependent on the $\mathrm{w} / \mathrm{c}$ ratio and the $\mathrm{F} / \mathrm{T}$ ratio. At a fixed $\mathrm{w} / \mathrm{c}$ ratio, the maximum filling height was higher at a higher $\mathrm{F} / \mathrm{T}$ ratio, albeit requiring a higher SP dosage to achieve the
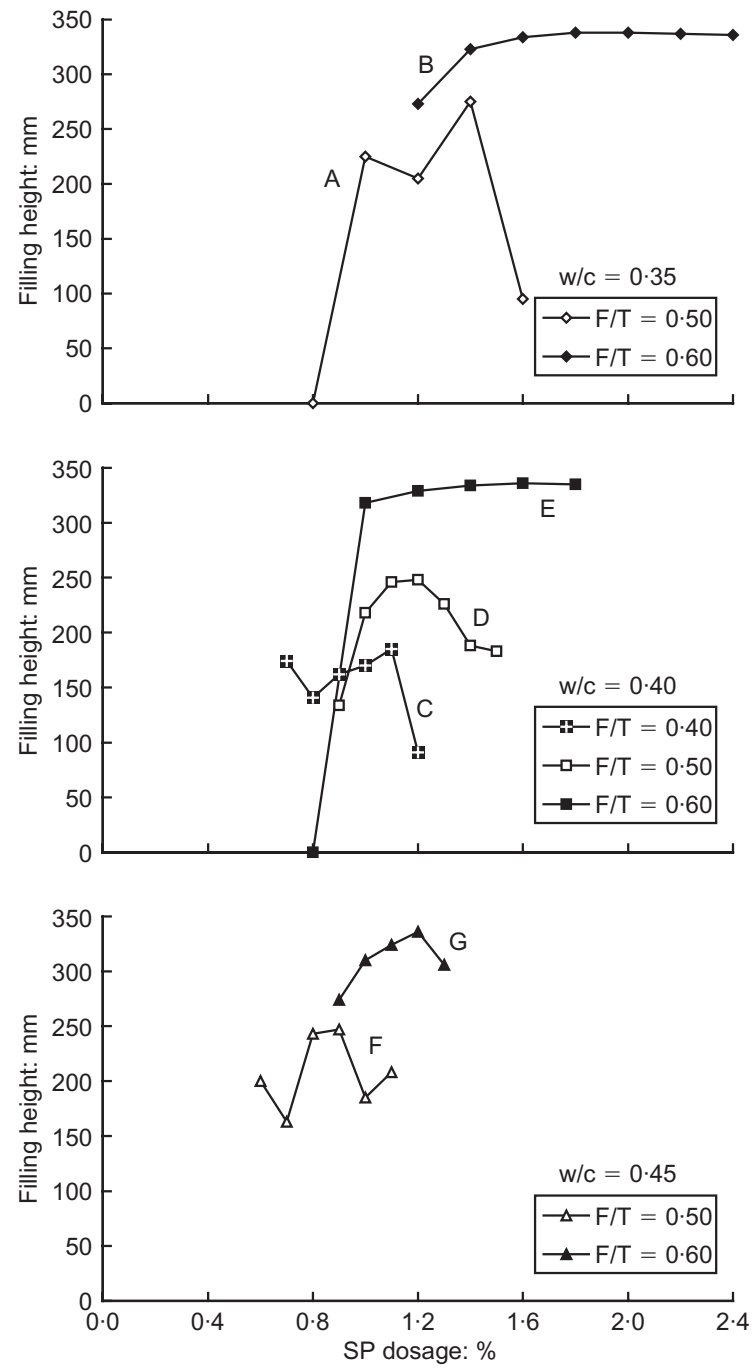

Figure 3. Filling height plotted against SP dosage

maximum filling height. On the other hand, at a fixed $\mathrm{F} / \mathrm{T}$ ratio, the maximum filling height was higher at a lower $w / c$ ratio, albeit requiring a higher SP dosage to achieve the maximum filling height. Among the various concrete mixes, only those with $\mathrm{F} / \mathrm{T}$ ratio $=0.60$ (coarse aggregate content $=683 \mathrm{~kg} / \mathrm{m}^{3}$ ) were able to achieve a maximum filling height of at least $300 \mathrm{~mm}$; those with $\mathrm{F} / \mathrm{T}$ ratio $=0.40$ or 0.50 (coarse aggregate content $\geqslant 853 \mathrm{~kg} / \mathrm{m}^{3}$ ) were not able to achieve a filling height of at least $300 \mathrm{~mm}$ no matter how much SP was added. Hence, apart from optimising the SP dosage, appropriate aggregate proportioning is also important in the design of SCC mixes.

\section{Effect of superplasticiser on segregation stability}

The effect of superplasticiser on the segregation stability of the seven concrete mixes is depicted in Figure 4 by plotting the segregation index against the SP dosage. As before, the curves are grouped into three separate graphs according to the $\mathrm{w} / \mathrm{c}$ ratio of the concrete mix. From these curves, it can be seen that in all

Magazine of Concrete Research, 2009, 61, No. 4 

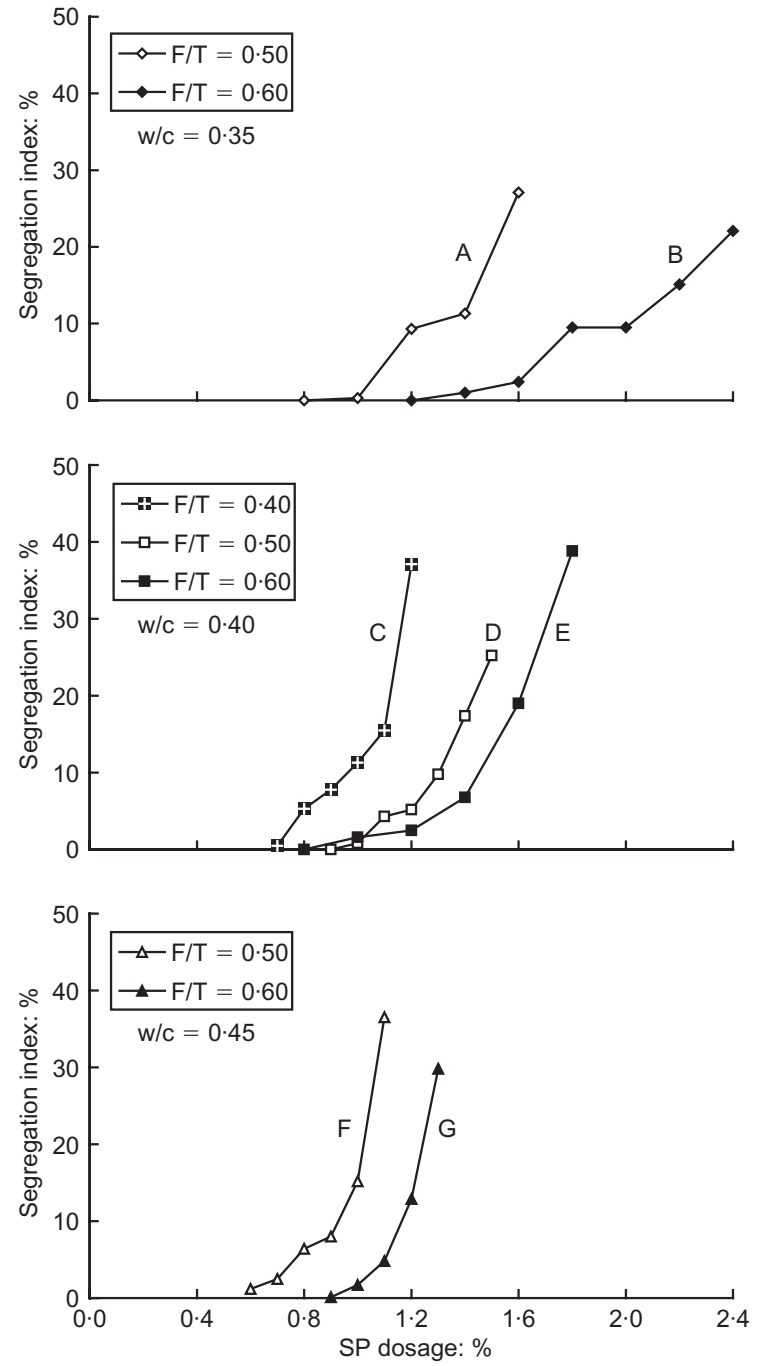

Figure 4. Segregation index plotted against SP dosage

the concrete mixes, as the SP dosage was increased, the segregation index steadily increased at a gradually increasing rate until the segregation index abruptly increased to higher than $20 \%$ when the SP dosage was only slightly further increased. At a given SP dosage, the segregation index was dependent on the $\mathrm{w} / \mathrm{c}$ ratio and the $\mathrm{F} / \mathrm{T}$ ratio. At a fixed $\mathrm{w} / \mathrm{c}$ ratio, the segregation index at any given SP dosage was lower at a higher $\mathrm{F} / \mathrm{T}$ ratio while at a fixed $\mathrm{F} / \mathrm{T}$ ratio, the segregation index at any given SP dosage was lower at a lower $\mathrm{w} / \mathrm{c}$ ratio. Hence, a higher $\mathrm{F} / \mathrm{T}$ ratio and/or a lower w/c ratio would render a higher cohesiveness for avoiding sedimentation of the coarse aggregate particles and segregation of the concrete mix.

\section{Effect of superplasticiser on strength}

The 28-day cube strength results of the 42 batches of concrete produced have been presented in the last column of Tables 4, 5 and 6. Each cube strength result was the mean strength of the three cubes cast from the same batch of concrete and tested at the same time. As the cubes were cast without compaction, these cube strength results represent the uncompacted cube strengths of the concrete. From these results, it can be seen that the maximum 28-day cube strengths achieved by the mixes $\mathrm{A}$ and $\mathrm{B}$ with $\mathrm{w} / \mathrm{c}=0 \cdot 35$, mixes $\mathrm{C}, \mathrm{D}$ and $\mathrm{E}$ with $\mathrm{w} / \mathrm{c}=0.40$, and mixes $\mathrm{F}$ and $\mathrm{G}$ with $\mathrm{w} / \mathrm{c}=0.45$ were $86 \mathrm{MPa}, 72 \mathrm{MPa}$ and $65 \mathrm{MPa}$, respectively. In all the concrete mixes, the cube strength increased with the SP dosage at a decreasing rate until a maximum value was reached at a relatively high SP dosage. This may be explained by the following two effects. First, it was observed during testing that when the SP dosage was low, the consolidation of the concrete in the cubes was actually incomplete, as indicated by the presence of many air voids on the surfaces of the cubes. However, when the SP dosage was relatively high such that the slump flow of the concrete mix was at least $650 \mathrm{~mm}$, the amount of air voids in each cube became insignificant. Hence, it is advocated that the minimum required slump flow for SCC should be taken as $650 \mathrm{~mm}$. Second, an increased SP dosage would better disperse the cement grains to avoid flocculation, thus resulting in a more uniform distribution of mixing water and a higher degree of hydration.

\section{Maximum performance and required SP dosage}

\section{Maximum slump flow without segregation}

From the experimental results, it is evident that in all the concrete mixes tested, as the slump flow was increased by adding more superplasticiser, the segregation index was also increased. Hence, generally, when the SP dosage is adjusted to maximise the overall performance, the workability or cohesiveness can only be increased at the expense of the other. It is therefore difficult to achieve both high workability and high cohesiveness at the same time. The variation of the segregation index with the slump flow as the SP dosage changes is illustrated in Figure 5, where the segregation index is plotted against the slump flow for the seven concrete mixes tested. It can be seen from this figure that when the slump flow is relatively low, the segregation index would slowly increase with the slump flow but when the slump flow is increased to beyond a certain limit, the segregation index would drastically increase to higher than $20 \%$, the acceptable upper limit for SCC. ${ }^{9}$ From the figure, the maximum slump flow without segregation, defined as the maximum slump flow with segregation index $\leqslant 20 \%$, of each concrete mix may be determined, as listed in the fourth column of Table 7. The required SP dosage for achieving the maximum slump flow without segregation of each concrete mix has also been determined, as listed in the fifth column of Table 7 . It is noteworthy that each of the seven concrete mixes has achieved a maximum 

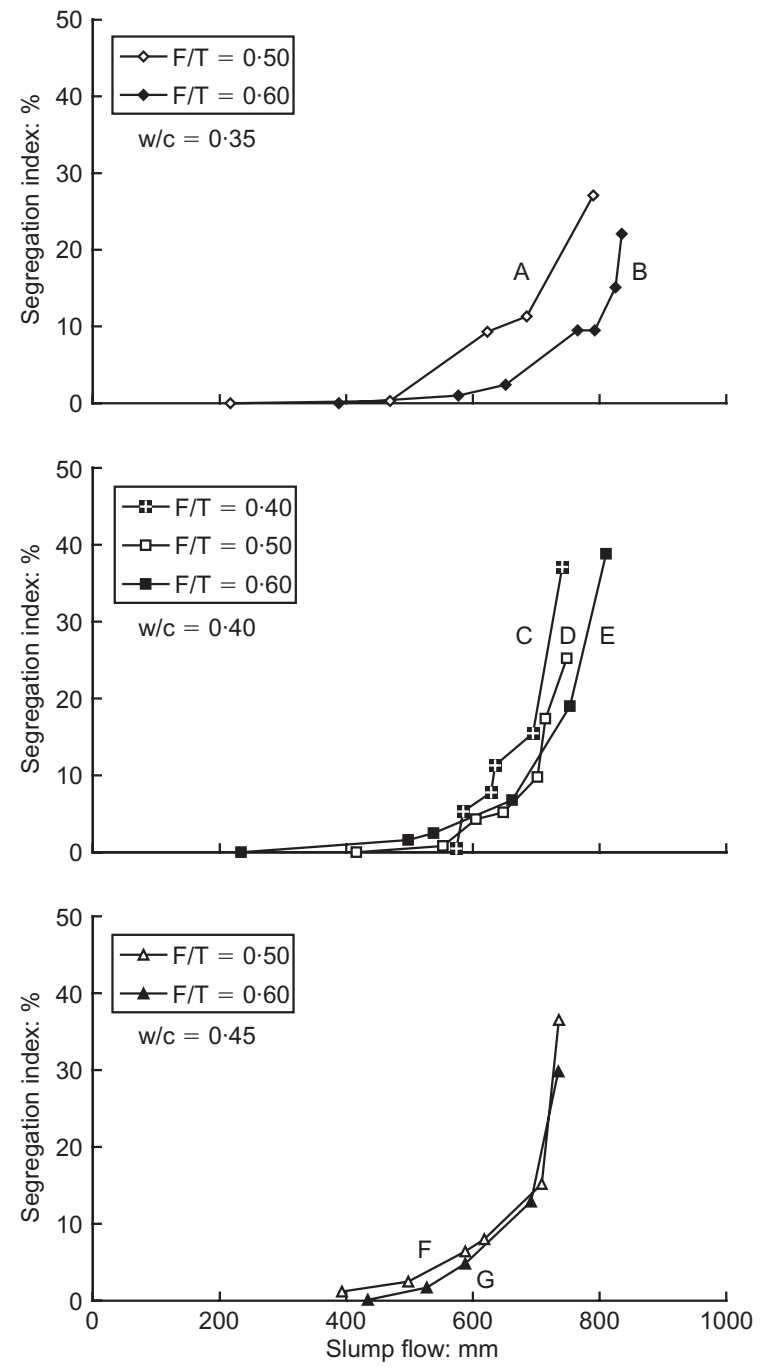

Figure 5. Segregation index plotted against slump flow

slump flow without segregation of well above $650 \mathrm{~mm}$, the minimum required for SCC advocated herein.

\section{Maximum filling height}

The experimental results also reveal that in all the concrete mixes tested, as the slump flow was increased by adding more superplasticiser, the filling height stea- dily increased but when the slump flow was increased to such extent that the segregation index became higher than about $15 \%$, the filling height drastically dropped. Hence, generally, for each concrete mix, there is a maximum achievable filling height. The variation of the filling height with the slump flow as the SP dosage changes is illustrated in Figure 6. It can be seen from
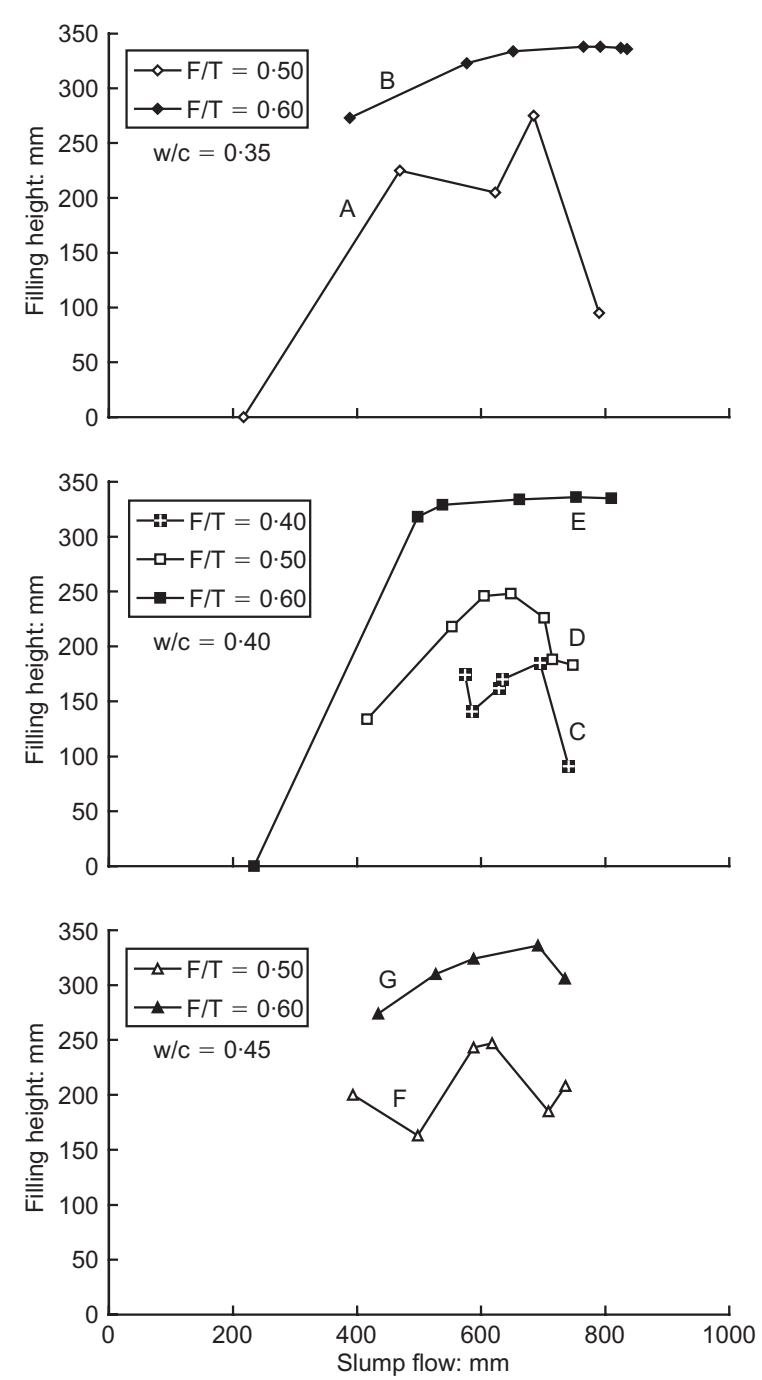

Figure 6. Filling height plotted against slump flow

Table 7. Maximum performance and required SP dosage

\begin{tabular}{|c|c|c|c|c|c|c|}
\hline \multirow[t]{2}{*}{ Mix No. } & \multirow[t]{2}{*}{$\mathrm{w} / \mathrm{c}$ ratio } & \multirow[t]{2}{*}{$\mathrm{F} / \mathrm{T}$ ratio } & \multicolumn{2}{|c|}{$\begin{array}{l}\text { Maximum slump flow with segregation index } \\
\qquad \leqslant 20 \%\end{array}$} & \multicolumn{2}{|c|}{$\begin{array}{l}\text { Maximum filling height for best passing/filling } \\
\text { abilities }\end{array}$} \\
\hline & & & $\begin{array}{l}\text { Maximum slump flow: } \\
\mathrm{mm}\end{array}$ & $\begin{array}{l}\text { Required SP dosage: } \\
\qquad \%\end{array}$ & $\begin{array}{l}\text { Maximum filling height: } \\
\mathrm{mm}\end{array}$ & $\begin{array}{l}\text { Required SP dosage: } \\
\qquad \%\end{array}$ \\
\hline A & 0.35 & 0.50 & 743 & 1.51 & 275 & 1.40 \\
\hline B & & $0 \cdot 60$ & 832 & $2 \cdot 34$ & 338 & $2 \cdot 00$ \\
\hline C & $0 \cdot 40$ & $0 \cdot 40$ & 705 & $1 \cdot 12$ & 185 & $1 \cdot 10$ \\
\hline D & & 0.50 & 726 & 1.43 & 248 & 1.20 \\
\hline E & & $0 \cdot 60$ & 756 & 1.62 & 336 & 1.60 \\
\hline $\mathrm{F}$ & 0.45 & 0.50 & 715 & 1.02 & 247 & 0.90 \\
\hline G & & $0 \cdot 60$ & 710 & $1 \cdot 24$ & 336 & $1 \cdot 20$ \\
\hline
\end{tabular}


this figure that the maximum filling height is dependent on both the $\mathrm{w} / \mathrm{c}$ ratio and the $\mathrm{F} / \mathrm{T}$ ratio and that the minimum required filling height of $300 \mathrm{~mm}$ for $\mathrm{SCC}^{20}$ is not always achievable. Furthermore, even when achievable, the filling height is higher than or equal to $300 \mathrm{~mm}$ only within a limited range of SP dosage or slump flow. The maximum filling height and the corresponding required SP dosage of each concrete mix are presented in the sixth and seventh columns of Table 7 . It should be noted that the maximum filling height and the maximum slump flow without segregation do not occur at the same time. Generally, the SP dosage for achieving maximum filling height is lower than the SP dosage for achieving maximum slump flow without segregation. The main reason is that the maximum filling height always occurs when the segregation index is lower than $20 \%$ while the maximum slump flow without segregation occurs when the segregation index is equal to $20 \%$.

\section{Effects of $w / c$ and $F / T$ ratios}

By nonlinear regression analysis of the data presented in the fourth and fifth columns of Table 7, the maximum slump flow without segregation and the required SP dosage may be expressed as multivariable quadratic functions of the $\mathrm{w} / \mathrm{c}$ and $\mathrm{F} / \mathrm{T}$ ratios, based on which the effects of the $\mathrm{w} / \mathrm{c}$ and $\mathrm{F} / \mathrm{T}$ ratios can be illustrated graphically in the form of contours, as shown in Figure 7. From this figure, it can be seen that the maximum slump flow without segregation is generally higher at a lower $\mathrm{w} / \mathrm{c}$ ratio or a higher $\mathrm{F} / \mathrm{T}$ ratio. Hence, although at a given SP dosage, the slump flow is lower at a lower w/c ratio or a higher F/T ratio (see Figure 2), when the SP dosage is allowed to vary in order to achieve maximum performance, the maximum slump flow without segregation that can be achieved is actually higher at a lower $\mathrm{w} / \mathrm{c}$ ratio or a higher $\mathrm{F} / \mathrm{T}$ ratio. There is, however, a price to pay. The required SP

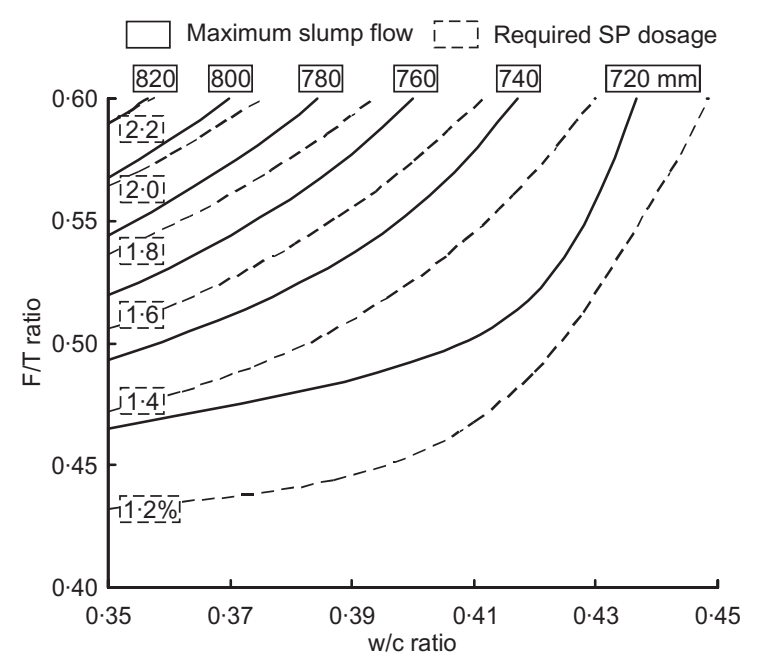

Figure 7. Maximum flow without segregation and required SP dosage dosage for achieving the maximum slump flow without segregation is also generally higher at a lower w/c ratio or a higher $\mathrm{F} / \mathrm{T}$ ratio.

Likewise, by nonlinear regression analysis of the data presented in the sixth and seventh columns of Table 7 , the effects of the $\mathrm{w} / \mathrm{c}$ and $\mathrm{F} / \mathrm{T}$ ratios on the maximum filling height and the required SP dosage can be illustrated graphically in the form of contours, as shown in Figure 8. From this figure, it can be seen that the maximum filling height is generally higher at a lower w/c ratio or a higher $\mathrm{F} / \mathrm{T}$ ratio. Relatively, the $\mathrm{F} / \mathrm{T}$ ratio has a greater effect than the $\mathrm{w} / \mathrm{c}$ ratio. In fact, for the ranges of mix parameters covered in this study (more explicitly, for concrete mixes with cement used as the only cementitious material and $\mathrm{w} / \mathrm{c}$ ratio within 0.35 and 0.45 ), the minimum required filling height of $300 \mathrm{~mm}$ for SCC is achievable only at an $\mathrm{F} / \mathrm{T}$ ratio higher than 0.55 regardless of the $\mathrm{w} / \mathrm{c}$ ratio. Hence, if the maximum filling height is lower than the minimum required, the filling height should be more effectively increased by increasing the $\mathrm{F} / \mathrm{T}$ ratio rather than by decreasing the w/c ratio. As expected, the required SP dosage for achieving the maximum filling height is generally higher at a lower $\mathrm{w} / \mathrm{c}$ ratio or a higher $\mathrm{F} / \mathrm{T}$ ratio.

\section{Robustness and optimum SP dosage}

\section{Acceptable range of SP dosage and optimum SP dosage}

To be qualified as SCC, the concrete mix has to satisfy all the following performance requirements: slump flow $\geqslant 650 \mathrm{~mm}$; segregation index $\leqslant 20 \%$; and filling height $\geqslant 300 \mathrm{~mm}$. From the experimental results, the range of SP dosage satisfying the requirements that slump flow $\geqslant 650 \mathrm{~mm}$ and segregation index $\leqslant 20 \%$ for each concrete mix has been determined and presented in the fourth column of Table 8 .

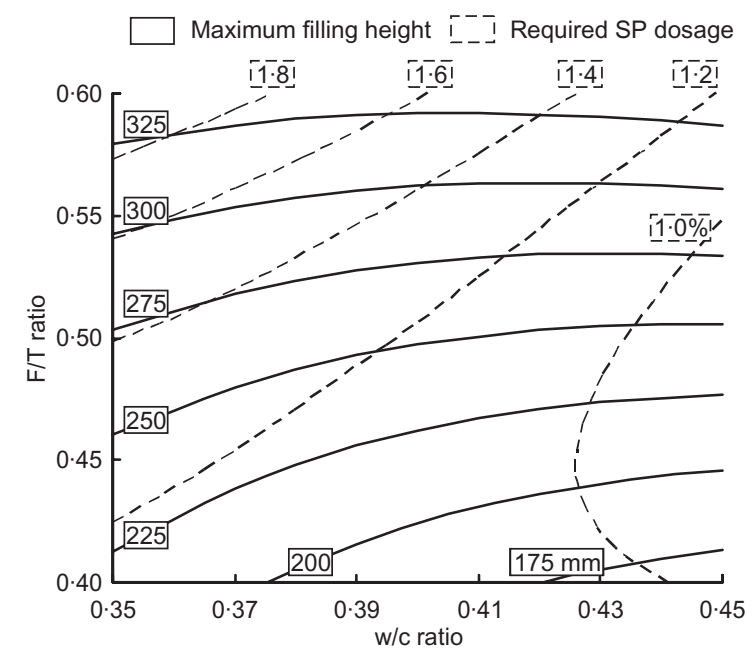

Figure 8. Maximum filling height and required SP dosage 
Table 8. Acceptable range of SP dosage and optimum SP dosage

\begin{tabular}{|c|c|c|c|c|c|c|}
\hline \multirow[t]{2}{*}{ Mix No. } & \multirow[t]{2}{*}{$\mathrm{w} / \mathrm{c}$ ratio } & \multirow[t]{2}{*}{$\mathrm{F} / \mathrm{T}$ ratio } & \multicolumn{2}{|c|}{$\begin{array}{c}\text { Range of SP dosage satisfying following } \\
\text { requirements: \% }\end{array}$} & \multicolumn{2}{|c|}{$\begin{array}{l}\text { SP dosage satisfying } \\
\text { all requirements: } \%\end{array}$} \\
\hline & & & $\begin{array}{l}\text { Slump flow } \geqslant 650 \mathrm{~mm} \\
\text { and segregation index } \\
\leqslant 20 \%\end{array}$ & $\begin{array}{l}\text { Filling height } \\
\geqslant 300 \mathrm{~mm}\end{array}$ & $\begin{array}{l}\text { Acceptable range of } \\
\text { SP dosage }\end{array}$ & $\begin{array}{l}\text { Optimum } \\
\text { SP dosage }\end{array}$ \\
\hline $\mathrm{A}$ & $0 \cdot 35$ & $0 \cdot 50$ & $1 \cdot 29-1.51$ & - & - & - \\
\hline B & & 0.60 & $1 \cdot 59-2 \cdot 34$ & $1 \cdot 31-2 \cdot 40$ & $1 \cdot 59-2 \cdot 34$ & 1.97 \\
\hline $\mathrm{C}$ & $0 \cdot 40$ & $0 \cdot 40$ & $1 \cdot 03-1 \cdot 12$ & - & - & - \\
\hline $\mathrm{D}$ & & $0 \cdot 50$ & $1 \cdot 20-1.43$ & - & - & - \\
\hline $\mathrm{E}$ & & 0.60 & $1 \cdot 38-1.62$ & $0.99-1.80$ & $1 \cdot 38-1.62$ & $1 \cdot 50$ \\
\hline $\mathrm{F}$ & $0 \cdot 45$ & $0 \cdot 50$ & $0.94-1.02$ & - & - & - \\
\hline G & & 0.60 & $1 \cdot 16-1 \cdot 24$ & $0.97-1.30$ & $1 \cdot 16-1 \cdot 24$ & 1.20 \\
\hline
\end{tabular}

Likewise, the range of SP dosage satisfying the requirement that filling height $\geqslant 300 \mathrm{~mm}$ for each concrete mix has been determined and presented in the fifth column of Table 8 (note that since the mixes A, C, D and $\mathrm{F}$ do not satisfy this requirement, no range is given for them). Combining these ranges of SP dosage, the acceptable range of SP dosage satisfying all the requirements for SCC can be obtained, as listed in the sixth column of Table 8 . The breadth of such acceptable range of SP dosage may be taken as a quantitative measure of robustness. The robustness of a concrete mix may be said to be high if the acceptable range of SP dosage satisfying all requirements is relatively wide because a wider acceptable range of SP dosage would render the performance of the concrete mix less sensitive to changes in SP dosage. Comparing the acceptable ranges of SP dosage in Table 8, it can be seen that the robustness is generally higher at a lower $\mathrm{w} / \mathrm{c}$ ratio or a higher $\mathrm{F} / \mathrm{T}$ ratio.

To allow the largest increase or decrease in the SP dosage without causing the concrete mix to fail as an SCC, the design SP dosage should be set as the middle value of the acceptable range of SP dosage. Such a design SP dosage is actually the optimum SP dosage for maximum robustness of the concrete mix. The optimum SP dosage so evaluated for each concrete mix is presented in the last column of Table 8. Comparing the optimum SP dosage of each concrete mix with the respective required SP dosage for maximum filling height (given in last column of Table 7), it is evident that in every concrete mix acceptable as an SCC, the optimum SP dosage is very close to the required SP dosage for maximum filling height. Hence, an alternative is simply to set the optimum SP dosage as the required SP dosage for maximum filling height. However, it should be noted that the design SP dosage should never be set as the required SP dosage for maximum slump flow without segregation because such a design SP dosage would lead to serious segregation (segregation index $>20 \%$ ) upon the slightest increase in SP dosage and thus a very low robustness.

\section{Acceptable range of slump flow}

Following the same procedures, the range of slump flow satisfying the requirements that slump flow $\geqslant 650 \mathrm{~mm}$ and segregation index $\leqslant 20 \%$ for each concrete mix has been determined and presented in the fourth column of Table 9. Likewise, the range of slump flow satisfying the requirement that filling height $\geqslant 300 \mathrm{~mm}$ for each concrete mix has been determined

Table 9. Acceptable range of slump flow and robustness

\begin{tabular}{|c|c|c|c|c|c|c|}
\hline \multirow[t]{2}{*}{ Mix No. } & \multirow[t]{2}{*}{ w/c ratio } & \multirow[t]{2}{*}{$\mathrm{F} / \mathrm{T}$ ratio } & \multicolumn{2}{|c|}{$\begin{array}{l}\text { Range of slump flow satisfying following } \\
\text { requirements: } \mathrm{mm}\end{array}$} & \multirow{2}{*}{$\begin{array}{l}\text { Acceptable range of } \\
\text { slump flow satisfying } \\
\text { all requirements: } \mathrm{mm}\end{array}$} & \multirow{2}{*}{$\begin{array}{c}\text { Robustness taken as } \\
\text { breadth of acceptable } \\
\text { range of slump flow: } \\
\mathrm{mm}\end{array}$} \\
\hline & & & $\begin{array}{c}\text { Slump flow } \geqslant 650 \mathrm{~mm} \\
\text { and segregation index } \\
\leqslant 20 \%\end{array}$ & $\begin{array}{l}\text { Filling height } \geqslant \\
\quad 300 \mathrm{~mm}\end{array}$ & & \\
\hline A & $0 \cdot 35$ & 0.50 & $650-743$ & - & - & 0 \\
\hline B & & $0 \cdot 60$ & $650-832$ & $490-835$ & $650-832$ & 182 \\
\hline $\mathrm{C}$ & $0 \cdot 40$ & 0.40 & $650-705$ & - & - & 0 \\
\hline D & & $0 \cdot 50$ & $650-726$ & - & - & 0 \\
\hline $\mathrm{E}$ & & 0.60 & $650-756$ & $483-810$ & $650-756$ & 106 \\
\hline $\mathrm{F}$ & $0 \cdot 45$ & $0 \cdot 50$ & $650-715$ & - & - & 0 \\
\hline G & & 0.60 & $650-710$ & $501-735$ & $650-710$ & 60 \\
\hline
\end{tabular}


and presented in the fifth column of Table 9. Combining these ranges of slump flow, the acceptable range of slump flow satisfying all the requirements for SCC can be obtained, as listed in the sixth column of Table 9. The width of such acceptable range of slump flow may also be taken as a quantitative measure of robustness, as depicted in the last column of Table 9. In fact, it is the current authors' belief that the width of the acceptable range of slump flow should be a more objective measure of robustness than the width of the acceptable range of SP dosage because the acceptable range of SP dosage is actually dependent on the type and characteristic of the superplasticiser used. As before, the robustness values presented in Table 9, each expressed in terms of the width of the acceptable range of slump flow, reveal that the robustness is generally higher at a lower w/c ratio or a higher $\mathrm{F} / \mathrm{T}$ ratio.

It should be noted that the acceptable range of slump flow is a property of the concrete mix. Depending on the mix parameters, especially the composition of the cementitious materials and the particle size distribution of the aggregate, different concrete mixes may have very different acceptable ranges of slump flow. There is basically no single range of slump flow that is applicable to all concrete mixes. In fact, the relationship between passing/filling abilities and slump flow and the relationship between segregation stability and slump flow are both dependent on the mix parameters. The common practices of predicting the segregation tendency from the slump flow ${ }^{23}$ and of recommending a desirable range of slump flow ${ }^{24}$ are not universally applicable. In this regard, the authors always object to the idea of setting an upper limit to the slump flow for the purpose of ensuring sufficient cohesiveness. For a given concrete mix, the cohesiveness is generally lower at a higher workability and vice versa. A concrete mix having a higher workability does not, however, necessarily have a lower cohesiveness than another concrete mix having a lower workability. Depending on the mix optimisation technique applied, it may be possible to produce a concrete mix that has a higher slump flow than the specified or recommended upper limit and at the same time satisfies all the other requirements for SCC. The present authors do not see any reason for condemning a concrete mix just because its slump flow is higher than an artificially set upper limit.

\section{Conclusions}

A total of 42 batches of concrete, derived from seven basic mix proportions and containing different dosages of superplasticiser, were produced for studying the effects of SP dosage on the workability, passing/filling abilities, segregation stability and strength of concrete mixes with $\mathrm{w} / \mathrm{c}$ ratios ranging from 0.35 to 0.45 and $\mathrm{F} /$ $\mathrm{T}$ ratios ranging from $0 \cdot 40$ to $0 \cdot 60$. The slump flow, $\mathrm{U}-$ box, sieve segregation and cube compression tests were employed to measure the performance of the concrete mixes. Overall, the results revealed that the increase of SP dosage to increase the workability would cause gradual reduction of the cohesiveness and at a certain stage drastic reduction of the cohesiveness and passing/ filling abilities. Hence, the SP dosage has great effects on the performance of SCC and thus should be carefully selected.

The effects of SP dosage were found to be dependent on the $\mathrm{w} / \mathrm{c}$ and $\mathrm{F} / \mathrm{T}$ ratios. Regarding the workability and cohesiveness, although at a given SP dosage, the slump flow is lower at a lower w/c ratio or a higher $\mathrm{F} / \mathrm{T}$ ratio, when the SP dosage is optimised to achieve maximum performance, the maximum slump flow without segregation that can be achieved is actually higher at a lower $\mathrm{w} / \mathrm{c}$ ratio or a higher $\mathrm{F} / \mathrm{T}$ ratio. Regarding the passing and filling abilities, the maximum achievable filling height is generally higher at a lower w/c ratio or a higher $\mathrm{F} / \mathrm{T}$ ratio. Relatively, the $\mathrm{F} / \mathrm{T}$ ratio has greater effect on the maximum filling height than the $\mathrm{w} / \mathrm{c}$ ratio and therefore if the maximum filling height is lower than the minimum required, the filling height should be more effectively increased by increasing the $\mathrm{F} / \mathrm{T}$ ratio rather than by decreasing the $\mathrm{w} / \mathrm{c}$ ratio. The required SP dosage for achieving the maximum slump flow without segregation or maximum filling height is, however, also generally higher at a lower $\mathrm{w} / \mathrm{c}$ ratio or a higher $\mathrm{F} / \mathrm{T}$ ratio.

Based on observation of excessive voids in uncompacted concrete at slump flow $<650 \mathrm{~mm}$ and recommendations of JSCE Guidelines ${ }^{20}$ and European Guidelines, ${ }^{9}$ it is suggested that the requirements for SCC should be: slump flow $\geqslant 650 \mathrm{~mm}$; segregation index $\leqslant 20 \%$; and filling height $\geqslant 300 \mathrm{~mm}$. From the test results, the acceptable range of SP dosage satisfying all such requirements has been determined for each concrete mix. As a wider acceptable range of SP dosage would render the performance of the concrete mix less sensitive to changes in SP dosage, it is proposed to take the width of the acceptable range of SP dosage as a measure of robustness. Furthermore, it is proposed to take the middle value of the acceptable range of SP dosage as the optimum SP dosage for maximum robustness. Likewise, the acceptable range of slump flow satisfying the above requirements has also been determined for each concrete mix. It is proposed that this acceptable range of slump flow may also be taken as a measure of robustness. Taking the acceptable range of either SP dosage or slump flow as the measure of robustness, it can be seen that the robustness is generally higher at a lower $\mathrm{w} / \mathrm{c}$ ratio or a higher $\mathrm{F} / \mathrm{T}$ ratio. Hence, the adoption of a higher $\mathrm{F} / \mathrm{T}$ ratio would increase not only the maximum performance but also the robustness of the concrete mix. Finally, it is advocated that no upper limit should be imposed to the slump flow, as a concrete mix with a high robustness can have a high slump flow while satisfying all other requirements for SCC. 


\section{Acknowledgement}

The work described in this paper was fully supported by a grant from the Research Grants Council of the Hong Kong Special Administrative Region, China (Project No. HKU 7139/05E).

\section{References}

1. OKamura H. Self-compacting high-performance concrete. Concrete International, 1997, 19, No. 7, 50-54.

2. Goodier C. I. Development of self-compacting concrete. Proceedings of Institution of Civil Engineers, Structures and Buildings, 2003, 156, No. 4, 405-414.

3. Skarendahl $\AA$. Changing concrete construction through use of self-compacting concrete. In Design, Performance and Use of Self-Consolidating Concrete (SCC'2005-China) (Yu Z., SHI C., KhayAT K. H and XIE Y. (eds)). International Union of Testing and Research Laboratories for Materials and Structures (RILEM), Changsha, China, 2005, pp. 17-24.

4. Sonebi M., Grünewald S. and Walraven J. Filling ability and passing ability of self-consolidating concrete. ACI Materials Journal, 2007, 104, No. 2, 162-170.

5. Khayat K. H., Assaad J. and Daczko J. Comparison of fieldoriented test methods to assess dynamic stability of selfconsolidating concrete. ACI Materials Journal, 2004, 101, No. 2, 168-176.

6. OKamura H. and Ouchi M. Self-compacting concrete. Journal of Advanced Concrete Technology, 2003, 1, No. 1, 5-15.

7. Domone P. L. Self-compacting concrete: an analysis of 11 years of case studies. Cement and Concrete Composites, 2006, 28, No. 2, 197-208.

8. NG I. Y. T., Wong H. H. C. and Kwan A. K. H. Passing ability and segregation stability of self-consolidating concrete with different aggregate proportions. Magazine of Concrete Research, 2006, 58, No. 7, 447-457.

9. Self Compacting Concrete European Project Group. The European Guidelines for Self-Compacting Concrete. BIBM, CEMBUREAU, EFCA, EFNARC and ERMCO, 2005. Available online from: http://www.efnarc.org. Accessed 27/01/2009.

10. Nkinamubanzi P. C. and Aïtcin P. C. Cement and superplasticizer combinations: compatibility and robustness. Cement, Concrete and Aggregates, 2004, 26, No. 2, 102-109.

11. Nunes S., Figueiras H., Oliveira P. M., Coutinho J. S. and Figueiras J. A methodology to assess robustness of SCC mixtures. Cement and Concrete Research, 2006, 36, No. 12, 2115 2122 .
12. British Standards Institution. Specification for Portland Cement. BSI, London, 1996, BS 12.

13. British Standards Institution. Methods of Testing Cement. Determination of Strength. BSI, London, 2005, BS EN 196-1.

14. British Standards Institution. Specification for Aggregates from Natural Sources for Concrete. BSI, London, 1992, BS 882.

15. British Standards Institution. Concrete Admixtures. Specification for Superplasticizing Admixtures. BSI, London, 1985, BS 5075-3.

16. Meнta P. K. and AÏTcin P. C. Microstructural basis of selection of materials and mix proportions for high-strength concrete. Proceedings of the 2nd International Symposium on Utilization of High Strength Concrete. American Concrete Institute, Farmington Hills, MI, USA, 1990, ACI Special Publication SP-121, pp. $265-286$.

17. Hanehara S. and Yamada K. Interaction between cement and chemical admixture from point of cement hydration, absorption behaviour of admixture, and paste rheology. Cement and Concrete Research, 1999, 29, No. 8, 1159-1165.

18. British Standards Institution. Testing Concrete. Method for Determination of Slump. BSI, London, 1983, BS 1881-102.

19. International Union OF Testing AND Research Laboratories for Materials and Structures (RILEM). Self-Compacting Concrete (SKARENDAHL $\AA$. and PETERSSON Ö. (eds)). Technical Committee 174-SCC, RILEM Publications SARL, Bagneux, France, 2002.

20. JAPAn Society OF CIVIL EngineERs. JSCE Guidelines for Concrete No. 6: Standard Specifications for Concrete Structures 2002: Materials and Construction. Japan Society of Civil Engineers, Tokyo, 2005.

21. Fujiwara H. Fundamental study on the self-compacting property of high-fluidity concrete. Proceedings of Japan Concrete Institute, 1992, 14, No. 1, 27-32.

22. El-Chabib H. and Nehdi M. Effect of mixture design parameters on segregation of self-consolidating concrete. ACI Materials Journal, 2006, 103, No. 5, 374-383.

23. SAFawi M. I., IwaKi I. and MiUra T. A study on the applicability of vibration in fresh high fluidity concrete. Cement and Concrete Research, 2005, 35, No. 9, 1834-1845.

24. Hwang S., Khayat K. H. and Bonneau O. Performance-based specifications of self-consolidating concrete used in structural applications. ACI Materials Journal, 2006, 103, No. 2, $121-$ 129.

Discussion contributions on this paper should reach the editor by 1 November 2009 